\title{
The diabetic patient in Ramadan
}

Hassan Chamsi-Pasha, Khalid S. Aljabri

Departments of Cardiology and ' $E$ Endocrinology, Diabetes Centre, King Fahd Armed Forces Hospital, Jeddah, Kingdom of Saudi Arabia

\begin{tabular}{|c|}
\hline Access this article online \\
\hline Website: www.avicennajmed.com \\
\hline DOI: 10.4103/2231-0770.130341 \\
\hline Quick Response Code: \\
\hline
\end{tabular}

\section{ABSTRACT}

During the month of Ramadan, all healthy, adult Muslims are required to fast from dawn to sunset. Fasting during Ramadan involves abstaining from food, water, beverages, smoking, oral drugs, and sexual intercourse. Although the Quran exempts chronically ill from fasting, many Muslims with diabetes still fast during Ramadan. Patients with diabetes who fast during the month of Ramadan can have acute complications. The risk of complications in fasting individuals with diabetes increases with longer periods of fasting. All patients with diabetes who wish to fast during Ramadan should be prepared by undergoing a medical assessment and engaging in a structured education program to undertake the fast as safely as possible. Although some guidelines do exist, there is an overwhelming need for better designed clinical trials which could provide us with evidence-based information and guidance in the management of patients with diabetes fasting Ramadan.

Key words: Diabetes mellitus, fasting, Islam, Ramadan

\section{INTRODUCTION}

Fasting is practiced by adult, healthy Muslims in the month of Ramadan. During the fast, adult Muslims are required to refrain from all oral intake of food, water, beverages, or drugs, as well as from sexual intercourse, between dawn and sunset. Due to the nature of fasting, it may affect the glycemic control and/or compliance of the patient. ${ }^{[1]}$ Globally, approximately 50 million Muslims with diabetes fast for 1 month each year. ${ }^{[2]}$

Although some guidelines have been formulated, ${ }^{[3]}$ there is an obvious lack of specific guidelines for managing patients with diabetes fasting Ramadan. ${ }^{[4]}$

Although the Quran exempts sick people from the duty of fasting, many Muslims with diabetes may not perceive themselves as sick and are keen to fast. ${ }^{[5,6]} \mathrm{A}$ large epidemiological study of Muslims with diabetes in 13 Muslim countries $(n=12,914)$ - the epidemiology of diabetes and Ramadan (EPIDIAR) study showed that $43 \%$ of patients with type 1 and $79 \%$ of those with type 2 diabetes mellitus (T2DM) fasted during Ramadan. ${ }^{[7]}$
As the timing of Ramadan is based on the lunar calendar, Ramadan falls 10 days earlier annually. For the next decade, Ramadan will fall in the summer in the northern hemisphere. As daylight hours vary considerably between summer and winter months in non-equatorial countries, the length of the fast increases in the summer to about $16-20 \mathrm{~h}^{[8]}$

People with diabetes who fast are at risk of adverse events, and the risks may increase with longer fasting periods. Fasting may lead to hypoglycemia, hyperglycemia with or without ketoacidosis, thrombosis and dehydration. Most Muslims eat two meals, before sunrise (known as suhur) and after sunset (known as iftar). The EPIDIAR study found that the change in eating patterns during Ramadan increased risk of severe hypoglycemia 4.7 -fold (from 3 to 14 events/100 people/month) in type 1 diabetes mellitus (T1DM) and 7.5 -fold (from 0.4 to 3 events/ 100 people/month) in T2DM. ${ }^{[7]}$

Another problem is the reluctance of patients in taking their medications during the fast, therefore timing and dosage of anti-diabetic medications have to be adjusted for individual patients. ${ }^{[9]}$ 


\section{PRE-RAMADAN MEDICAL ASSESSMENT AND COUNSELING}

All patients with diabetes wishing to fast during Ramadan should receive proper counseling 1-2 months before the onset of Ramadan. Asking the patients not to fast, even though may be based on scientific evidence, may not only lead to the patient fasting without telling his doctor but may also offend the patient's cultural and religious values. The physicians should work with their patients to prepare an appropriate and individualized life-style, diet and drug plan. ${ }^{[1]}$

Assessment should include a full annual review, detection of complications along with measurements of hemoglobin A1c, blood pressure and lipids, as well as specific advice including potential risks of fasting. ${ }^{[10]}$

The management plan must be highly individualized and educational counseling should focus not only on the patient but also his or her family about the awareness of symptoms of hypo- and hyper-glycemias, planning of meals, blood glucose monitoring, physical activity as well as management of acute complications including when to break the fast. ${ }^{[1,2]}$

Patients should have the means to monitor their blood glucose levels multiple times daily, particularly in patients with T1DM and in patients with T2DM who require insulin.

In a large observational study, patients who fasted during Ramadan without attending a structured education session had a four-fold increase in hypoglycemic events, whereas those who attended an education program focusing on Ramadan had a significant decrease in hypoglycemic events. ${ }^{[2]}$

Most health problems are likely to arise from inappropriate diet or as a consequence of overeating and insufficient sleep. The common practice of ingesting large amounts of foods rich in carbohydrates and fats, especially at the sunset meal, should be discouraged. Meal at suhur should contain complex carbohydrate, as this will delay the digestion and absorption. This should be taken as late as possible. Fluid should be taken liberally during non-fasting hours.

Normal levels of physical activity may be maintained. However, excessive physical activity may lead to a higher risk of hypoglycemia and should be avoided.

All patients should understand that they must immediately end their fast if hypoglycemia (blood glucose of $<60 \mathrm{mg} / \mathrm{dl}$ [3.3 mmol/l]) occurs even minutes before sunset.
The fast should also be broken if blood glucose reaches $<70 \mathrm{mg} / \mathrm{dl}(3.9 \mathrm{mmol} / \mathrm{l})$ in the first few hours after the start of the fast, especially if insulin, sulfonylureas (SU) or combination of oral antihyperglycemic drugs are taken at suhur. The fast should also be broken if blood glucose exceeds $300 \mathrm{mg} / \mathrm{dl}(16.7 \mathrm{mmol} / \mathrm{l}){ }^{[2]}$ Both religious leaders and health care professionals are crucial in providing education and support for safer fasting during Ramadan. ${ }^{[11,12]}$

\section{MANAGEMENT OF PATIENTS WITH T2DM}

\section{Diet-controlled patients}

In patients with T2DM who are well-controlled with lifestyle therapy alone, the risk associated with fasting is quite low. However, there is still a potential risk for occurrence of postprandial hyperglycemia if patients overindulge in eating. ${ }^{[2]}$ Physical activity may be modified in its intensity and timing, e.g., $2 \mathrm{~h}$ after the sunset meal.

\section{Patients treated with oral agents Metformin}

Patients treated with metformin alone may safely fast because the possibility of severe hypoglycemia is minimal. Metformin dose should be split in a way that two-thirds of the dose is taken at iftar and one-third at suhur. ${ }^{[2,9]}$

Slow release formulations of metformin may be a better choice in fasting diabetic patients who are controlled on metformin and can be taken once daily after the sunset meal..$^{[1]}$

\section{Alpha-glucosidase inhibitors}

Acarbose, miglitol, and voglibose slow the absorption of carbohydrates when taken with the first bite of a meal. ${ }^{[13]}$ A randomized double blind study showed that the risk of hypoglycemia is low with this class of drugs, ${ }^{[14]}$ although no evidence that this is so during Ramadan.

\section{Glitazones}

The thiazolidinedione or glitazone agents (pioglitazone and rosiglitazone) are not independently associated with hypoglycemia, though they can amplify the hypoglycemic effects of SU, glinides, and insulin. These agents require 2-4 weeks to exert substantial antihyperglycemic effects. Therefore, these agents cannot be quickly substituted for agents associated with hypoglycemia during periods of fasting. ${ }^{[15]}$ Patients should be able to take these medications as usual with no adjustment in dosage required. ${ }^{[9]}$ For those on combination treatments the dose should be adjusted to take half the tablet at dawn and 1.5 at sunset. ${ }^{[10]}$ 


\section{Sulfonylureas}

It has been suggested that this group of drugs is unsuitable for use during fasting because of the inherent risk of hypoglycemia. Nevertheless, because of their world-wide use and relatively low cost, these agents may be used in Ramadan, though with caution. ${ }^{[2,16]}$

The use of chlorpropamide is relatively contraindicated during Ramadan because of the possibility of prolonged and unpredictable hypoglycemia. Glibenclamide use was claimed to be safe during Ramadan fasting. ${ }^{[17]}$ However, subsequently it has been suggested that glibenclamide and glyburide may be associated with a higher risk of hypoglycemia than other second-generation SU, specifically gliclazide, glimepiride, and glipizide. ${ }^{[18]}$ An open labeled prospective observational study from six countries looked at the use of glimepiride in 332 patients with T2DM and showed that the incidence of hypoglycemic episodes was 3\% in newly diagnosed patients and $3.7 \%$ in already treated patients. These figures were similar to the pre- and post-Ramadan periods. ${ }^{[19]}$ On the basis of the prospective study by the glimepiride in Ramadan study group, ${ }^{[19]}$ it is recommended that during Ramadan, clinicians change the timing of the once daily dose of SU (such as glimepiride) from the usual morning dose to the evening (at iftar). ${ }^{[9]}$ It will be prudent, however, to assume that long-acting oral hypoglycemic agents (OHA) must be used more cautiously than their short-acting counterparts during the fasting month. ${ }^{[20]}$

\section{Short-acting insulin secretagogues}

Members of this group (repaglinide and nateglinide) are useful because of their short duration of action. They could be taken twice daily before sunset and predawn meals. Nateglinide has the shortest duration of action and therefore the lowest risk of severe fasting hypoglycemia among the secretagogues. ${ }^{[2]}$ A randomized study showed that repaglinide contributed to improved glycemic control, with a lower number of hypoglycemic events among fasting patients during Ramadan when compared with glibenclamide. ${ }^{[21]}$

\section{Incretin-based therapies}

Therapies that affect the incretin system include glucagon-like peptide-1 (GLP-1) receptor agonists (exenatide and liraglutide) and dipeptidylpeptidase-4 inhibitors (DPP-4is) alogliptin, saxagliptin, sitagliptin, linagliptin and vildagliptin. ${ }^{[22]}$ They have been shown to cause less hypoglycemia as monotherapies when compared to conventional treatments and hence may be suitable for Ramadan.

Exenatide in particular can be given before meals to minimize appetite and promote weight loss. With its short half-life of $2 \mathrm{~h}$, it is not associated with a substantial effect on fasting glucose. The morning dose should be the same at iftar and the evening dose should be the same at suhur. The once weekly exanatide should not be used during fasting for fear of hypoglycemia.

Liraglutide is given once a day, independent of meals, and is more effective in controlling fasting glycemia. ${ }^{[2]}$ If the patient is on combination with OHA and GLP-1 analog, the dose of metformin need not be changed, but the dose of other OHA should be reduced. ${ }^{[22]}$

DPP-4is are among the best tolerated drugs for the treatment of diabetes. When used alone, they do not require any adjustments in their doses but the risk of hypoglycemia in combination with SU remains high. It may be safer, therefore, to combine DPP-4is with metformin, rather than $\mathrm{SU}$, in patients planning to fast Ramadan. ${ }^{[9]}$

Two of these agents have been studied during the Ramadan fast. A retrospective data audit of 100 patients taking $50 \mathrm{mg}$ of vildagliptin twice daily found that the incidence of hypoglycemia in such patients is less than that of patients with T2DM taking gliclazide during Ramadan. ${ }^{[23]}$ A small prospective study including 72 patients already taking vildagliptin (50 mg twice a day) or SU as add-on therapy to metformin during Ramadan fasting showed that with vildagliptin there were no hypoglycemic events reported as compared with nearly half of the patients in the SU group experiencing hypoglycemic events. ${ }^{[24]}$

More recently, a large multinational study, conducted in Asia and the Middle East, and included 1300 Muslim patients with T2DM who received treatment with vildagliptin (684) or SU (631) as add-on to metformin or monotherapy showed that vildagliptin was associated with significantly fewer hypoglycemic episodes compared with SU therapy (5.4\% vs. $19.8 \%$, respectively; $P<0.001)$. $^{[25]}$

Sitagliptin has been studied in large, randomized, controlled prospective trials of T2DM patients during Ramadan. In one study, 1066 adult patients with T2DM who were treated with stable doses of a SU with or without metformin for at least 3 months before screening and intended to fast during Ramadan were randomized to either switch to $100 \mathrm{mg} /$ day sitagliptin or remain on their pre-study SU. It was found that the risk of symptomatic or severe hypoglycemia in patients switched to a sitagliptin-based regimen was significantly decreased compared to those who remained on a SU-based regimen during Ramadan. ${ }^{[26]}$

In another study ${ }^{[27]}$ involving 848 patients who fasted Ramadan (421 on sitagliptin and 427 on SU) symptomatic 
hypoglycemic event during Ramadan was lower with sitagliptin (3.8\%) compared to SU (7.3\%). The authors concluded that switching antihyperglycemic treatment to sitagliptin from a SU reduced the risk of symptomatic hypoglycemia by approximately $50 \%$ in patients who fasted Ramadan. ${ }^{[27]}$

\section{Patients treated with insulin}

During fasting, human soluble insulins may remain in the system for 8-12 h and, with their late long-lasting peak starting $2 \mathrm{~h}$ after administration, can potentially lead to late postprandial hypoglycemia. Therefore, the newer insulin analog preparations may be more useful in managing diabetes during Ramadan. ${ }^{[10]}$

The general advice for long-acting insulin (glargine and detemir) is to reduce the dose by $20 \%$ to suppress output of glucose from the liver to near-normal levels during fasting and reduce the risk of hypoglycemia. ${ }^{[9,10]}$ Patients taking repaglinide and single dose glargine may continue taking the same doses of repaglinide but to be safer should consider reducing glargine by $20 \% \cdot{ }^{[9]}$ Long-acting insulin should be administered with the evening meal at dusk. Short-acting insulin analogs are also useful during fasting as they can work immediately following meals.

For premix insulins, the morning insulin dose should be taken at dusk and half of the evening dose should be taken at dawn. ${ }^{[10]}$ It is suggested that patients taking twice daily insulin should reduce the suhur dose by $30 \%$ if they are well-controlled, and consider switching to a mix $\times 50$ preparation if their postprandial glucose remains raised..$^{[9]}$ In general, the problems facing patients with T2DM who administer insulin are similar to those with T1DM, except that the incidence of hypoglycemia is less. Very elderly patients with T2DM and patients with renal insufficiency may be at high risk. ${ }^{[2]}$

\section{MANAGEMENT OF PATIENTS WITH T1DM}

Fasting at Ramadan carries a very high risk for people with T1DM. This risk is particularly exacerbated in poorly controlled patients and those with limited access to medical care, hypoglycemic unawareness, unstable glycemic control, or recurrent hospitalizations. In addition, the risk is also very high in patients who are unwilling or unable to monitor their blood glucose levels several times daily.

Most studies of patients with T1DM have comprised small numbers of patients and some have excluded adolescents, or patients with comorbidities such as renal impairment. Suggested treatments, therefore, may not be generalized to all fasting patients with T1DM, and no good evidence exists to allow giving clear guidance for those who are not on a basal-bolus regimen. ${ }^{[9,12]}$

The current understanding is that basal-bolus regimen is the preferred protocol of management. Patients with T1DM who are on a basal-bolus regimen 4 times daily should be discouraged from fasting owing to the risks of poor glycemic control. If patients choose to fast despite medical advice, it will help if they are familiar with carbohydrate counting. Adolescents with T1DM on a basal-bolus regimen should reduce their basal insulin by $20 \%$ to prevent hypoglycemia. The fast should be broken immediately if the blood glucose falls below $4 \mathrm{mmol} / \mathrm{l}$ or if they develop ketones. ${ }^{[28]}$

Insulin pump therapy (using a Medtronic MiniMed 722 model) was observed in 49 type 1 patients who fasted during Ramadan. 17 patients had hypoglycemia requiring breaking the fast but no severe hypoglycemia was reported. ${ }^{[29]}$

\section{PREGNANCY AND FASTING DURING RAMADAN}

Despite that pregnant Muslim women are exempt from fasting during Ramadan many healthy women fast Ramadan and even some with known diabetes mellitus (type 1, type 2, or gestational) insist on fasting. ${ }^{[30,31]}$

In general, women with pregestational or gestational diabetes are at very high risk, and are strongly advised not to fast during Ramadan since fasting may be associated with risks to both mother and fetus. ${ }^{[30]}$

\section{CONCLUSION}

A significant number of patients with diabetes insist on fasting during Ramadan against the advice of their doctors. Fasting in patients with diabetes can be associated with increased risk of both hypoglycemia and hyperglycemia. A systematic pre-Ramadan assessment with appropriate therapeutic adjustments and educational advice regarding healthy diet, exercise and awareness of the risks of hypo- and hyper-glycemia are important for patients with diabetes intending to fast during Ramadan. Despite the presence of some pragmatic guidelines, the importance of developing solid international and national guidelines to assist patients who want to fast on religious occasions cannot be overemphasized.

\section{REFERENCES}

1. Niazi AK, Kalra S. Patient centred care in diabetology: An Islamic perspective from South Asia. J Diabetes Metab Disord 2012;11:30.

2. Bravis V, Hui E, Salih S, Mehar S, Hassanein M, Devendra D. Ramadan Education and Awareness in Diabetes (READ) programme for 
Muslims with Type 2 diabetes who fast during Ramadan. Diabet Med 2010;27:327-31.

3. Al-Arouj M, Assaad-Khalil S, Buse J, Fahdil I, Fahmy M, Hafez S, et al. Recommendations for management of diabetes during Ramadan: Update 2010. Diabetes Care 2010;33:1895-902.

4. Hitman GA. Fasting, Ramadan and diabetes. Diabet Med 2012;29:695.

5. The Holy Quran 2:183-5.

6. Chamsi-Pasha H, Albar MA. Fasting Ramadan from Islamic and Medical Perspective. Jeddah: Al-Dar Al-Saudia; 2005.

7. Salti I, Bénard E, Detournay B, Bianchi-Biscay M, Le Brigand C, Voinet C, et al. A population-based study of diabetes and its characteristics during the fasting month of Ramadan in 13 countries: Results of the epidemiology of diabetes and Ramadan 1422/2001 (EPIDIAR) study. Diabetes Care 2004;27:2306-11.

8. Ghouri N, Gatrad R, Sattar N, Dhami S, Sheikh A. Summer-winter switching of the Ramadan fasts in people with diabetes living in temperate regions. Diabet Med 2012;29:696-7.

9. Hui E, Bravis V, Hassanein M, Hanif W, Malik R, Chowdhury TA, et al. Management of people with diabetes wanting to fast during Ramadan. BMJ 2010;340:c3053.

10. Karamat MA, Syed A, Hanif W. Review of diabetes management and guidelines during Ramadan. J R Soc Med 2010;103:139-47.

11. Beshyah SA. Fasting during the month of Ramadan for people with diabetes: Medicine and Fiqh united at last. Ibnosina J Med Biomed Sci 2009; 1:58-60.

12. Hui E, Devendra D. Diabetes and fasting during Ramadan. Diabetes Metab Res Rev 2010;26:606-10.

13. Van de Laar FA, Lucassen PL, Akkermans RP, Van de Lisdonk EH, Rutten GE, Van Weel C. Alpha-glucosidase inhibitors for type 2 diabetes mellitus. Cochrane Database Syst Rev 2005;2:CD003639.

14. Pan C, Yang W, Barona JP, Wang Y, Niggli M, Mohideen P, et al. Comparison of vildagliptin and acarbose monotherapy in patients with Type 2 diabetes: A 24-week, double-blind, randomized trial. Diabet Med 2008;25:435-41.

15. Retnakaran R, Zinman B. Thiazolidinediones and clinical outcomes in type 2 diabetes. Lancet 2009;373:2088-90.

16. Bashir MI, Pathan MF, Raza SA, Ahmad J, Khan AK, Ishtiaq O, et al. Role of oral hypoglycemic agents in the management of type 2 diabetes mellitus during Ramadan. Indian J Endocrinol Metab 2012;16:503-7.

17. Belkhadir J, el Ghomari H, Klöcker N, Mikou A, Nasciri M, Sabri M. Muslims with non-insulin dependent diabetes fasting during Ramadan: Treatment with glibenclamide. BMJ 1993;307:292-5.

18. Rendell $\mathrm{M}$. The role of sulphonylureas in the management of type 2 diabetes mellitus. Drugs 2004;64:1339-58.

19. Glimepiride in Ramadan (GLIRA) Study Group. The efficacy and safety of glimepiride in the management of type 2 diabetes in Muslim patients during Ramadan. Diabetes Care 2005;28:421-2.

20. Velayudhan M. Managing diabetes during the Muslim fasting month of Ramadan. Med J Malaysia 2012;67:353-4.

21. Mafauzy M. Repaglinide versus glibenclamide treatment of Type 2 diabetes during Ramadan fasting. Diabetes Res Clin Pract 2002;58:45-53.

22. Pathan MF, Sahay RK, Zargar AH, Raza SA, Khan AK, Siddiqui NI, et al. South Asian Consensus Guideline: Use of GLP-1 analogue therapy in diabetes during Ramadan. Indian J Endocrinol Metab 2012;16:525-7.

23. Devendra D, Gohel B, Bravis V, Hui E, Salih S, Mehar S, et al. Vildagliptin therapy and hypoglycaemia in Muslim type 2 diabetes patients during Ramadan. Int J Clin Pract 2009;63:1446-50.

24. Hanif W, Malik W, Hassanein M, Kamal A, Geransar P, Andrews C, et al. Treatment adherence with vildagliptin compared to sulphonylurea as add-on to metformin in Muslim patients with type 2 diabetes mellitus fasting during Ramadan. Curr Med Res Opin 2013;29:807-11.

25. Al-Arouj M, Hassoun AA, Medlej R, Pathan MF, Shaltout I, Chawla MS, et al. The effect of vildagliptin relative to sulphonylureas in Muslim patients with type 2 diabetes fasting during Ramadan: The VIRTUE study. Int J Clin Pract 2013;67:957-63.

26. Al Sifri S, Basiounny A, Echtay A, Al Omari M, Harman-Boehm I, Kaddaha G, et al. The incidence of hypoglycaemia in Muslim patients with type 2 diabetes treated with sitagliptin or a sulphonylurea during Ramadan: A randomised trial. Int J Clin Pract 2011;65:1132-40.

27. Aravind SR, Ismail SB, Balamurugan R, Gupta JB, Wadhwa T, Loh SM, et al. Hypoglycemia in patients with type 2 diabetes from India and Malaysia treated with sitagliptin or a sulfonylurea during Ramadan: A randomized, pragmatic study. Curr Med Res Opin 2012;28:1289-96.

28. Al-Khawari M, Al-Ruwayeh A, Al-Doub K, Allgrove J. Adolescents on basal-bolus insulin can fast during Ramadan. Pediatr Diabetes 2010;11:96-100.

29. Benbarka MM, Khalil AB, Beshyah SA, Marjei S, Awad SA. Insulin pump therapy in Moslem patients with type 1 diabetes during Ramadan fasting: An observational report. Diabetes Technol Ther 2010;12:287-90.

30. Hui E, Reddy M, Bravis V, Rahman M, Darko D, Hassanein M. Fasting among pregnant women with diabetes during Ramadan. Int J Clin Pract 2012;66:910-1.

31. Kridli SA. Health beliefs and practices of Muslim women during Ramadan. MCN Am J Matern Child Nurs 2011;36:216-21.

Cite this article as: Chamsi-Pasha $\mathrm{H}$, Aljabri KS. The diabetic patient in Ramadan. Avicenna J Med 2014;4:29-33.

Source of Support: Nil, Conflict of Interest: None declared.

Announcement

\section{“QUICK RESPONSE CODE” LINK FOR FULL TEXT ARTICLES}

The journal issue has a unique new feature for reaching to the journal's website without typing a single letter. Each article on its first page has a "Quick Response Code". Using any mobile or other hand-held device with camera and GPRS/other internet source, one can reach to the full text of that particular article on the journal's website. Start a QR-code reading software (see list of free applications from http://tinyurl.com/yzlh2tc) and point the camera to the QR-code printed in the journal. It will automatically take you to the HTML full text of that article. One can also use a desktop or laptop with web camera for similar functionality. See http://tinyurl.com/2bw7fn3 or http://tinyurl.com/3ysr3me for the free applications. 